\title{
How Do Speed and Security Influence Consumers' Payment Behavior?
}

\author{
Scott Schuh and Joanna Stavins
}

\begin{abstract}
:
The Federal Reserve named improvements in the speed and security of the payment system as two of its policy initiatives for 2012-2016. Using new data from the 2013 Survey of Consumer Payment Choice (SCPC) and models from earlier research, we estimate how various aspects of speed and security influence consumers' decisions to adopt and use payment instruments. Some aspects of speed and security have a statistically significant influence on the adoption and use of selected payment instruments, but not as much as other characteristics of payment instruments. Using econometric models to simulate selected policies proposed by the Fed, we show that faster speed of payment deduction for Automatic Clearing House (ACH) transactions would slightly increase consumers' adoption of $\mathrm{ACH}$-based payment methods, while enhanced security of payment cards would marginally increase the use of credit and debit cards. However, neither improvement is likely to increase consumer welfare much because consumer demand for payments is very inelastic with respect to speed and security. Our analysis focuses exclusively on consumers' behavior and does not include potential benefits of improvements to the payment system that would directly benefit businesses or financial institutions. In addition, preventing security breaches may preserve public confidence in the payment system, benefitting consumers even if they do not change their payment behavior.
\end{abstract}

\section{JEL Classifications: D12, D14, E58}

Scott Schuh is the Director of the Consumer Payments Research Center and an economist in the research department of the Federal Reserve Bank of Boston, and Joanna Stavins is a senior economist and policy advisor in the Consumer Payments Research Center in the research department of the Federal Reserve Bank of Boston. Their e-mail addresses arescott.schuh@bos.frb.org and joanna.stavins@bos.frb.org, respectively.

This brief, which may be revised, is available on the web site of the Federal Reserve Bank of Boston at http://www.bostonfed.org/economic/current-policy-perspectives/index.htm.

Fumiko Hayashi, Zach Markiewicz, Will Roberds, and Bob Triest provided helpful comments, and Sean Connolly provided excellent research assistance.

The views expressed in this brief are those of the author and do not necessarily represent the views of the Federal Reserve Bank of Boston or the Federal Reserve System.

This version: February 5, 2015

\begin{tabular}{|l|l|l}
\hline $\mathrm{C}$ & $\mathrm{P}$ & $\begin{array}{l}\text { CONSUMER PAYMENTS } \\
\text { Research Center }\end{array}$ \\
\hline $\mathrm{R}$ & $\mathrm{C}$ & Reser \\
\hline
\end{tabular}




\section{Background}

In October 2012, Federal Reserve Financial Services (FRFS) issued its updated strategic plan for 2012-2016. The strategic plan emphasized enhancing end-to-end speed, security, and efficiency as the most important initiatives for payments in the next several years, where end-to-end means that for the first time end users are explicitly included. In September 2013, FRFS released "Payment System Improvement-Public Consultation Paper"1 to solicit public feedback on its strategic direction. In addition, the Federal Reserve commissioned consumer market research to assess consumer preferences related to the speed of payments. Based on public comments received on the consultation paper and on the results of the market research study, the FRFS released a new paper, "Advancing the Federal Reserve Financial Services Strategic Direction," in June 2014. Using industry input and research done so far, the Federal Reserve has recently released a followup paper, "Strategies for Improving the U.S. Payment System." ${ }^{3}$ Note that because the final strategy paper is currently under discussion by Federal Reserve policymakers, all the policies and strategies discussed here are preliminary.

The feedback received by the Federal Reserve specifically identified a need for further research, noting that, "Recognition by many that more frequent and higher-quality information and research are critical to the industry." 4 The market research on end users' preferences commissioned by the Federal Reserve revealed that not all the features of speed and security are important and that none of these features is important to all consumers. While these findings are interesting, they do not provide sufficient guidance about how implementing relevant new policies would alter consumers' payment behavior and hence increase consumer welfare. Our analysis helps to address this gap.

Economists have also studied the question of how some of the characteristics of payment instruments, such as speed and security, affect consumer decisions to adopt and use these

${ }^{1}$ http://fedpaymentsimprovement.org/wp-content/uploads/2013/09/Payment System Improvement Public Consultation_Paper.pdf

${ }^{2}$ http://fedpaymentsimprovement.org/wp-content/uploads/frfs-june-2014-town-hall.pdf

${ }^{3}$ https://fedpaymentsimprovement.org/wp-content/uploads/strategies-improving-us-payment-system.pdf

${ }^{4}$ http://fedpaymentsimprovement.org/wp-content/uploads/frfs-june-2014-town-hall.pdf 
payment instruments. Such characteristics have been found to be important in explaining why consumers adopt and use the payment instruments they do. Convenience and cost have been found to be especially strong factors affecting payment behavior, although record keeping and security have also significantly influenced the adoption and/or the use of selected payment instruments. $^{5}$

To evaluate how potential improvements in speed or security would increase consumer welfare, the Consumer Payments Research Center at the Boston Fed conducted a detailed survey of consumers on their valuation of specific aspects of speed and security in 2013, as part of its annual Survey of Consumer Payment Choice (SCPC annual surveys, from 2008 to 2014). ${ }^{6}$ Using the results of the SCPC survey conducted in the fall of 2013 and the models of Schuh and Stavins (2010, 2013), this paper explores in greater detail which specific aspects of speed and security of payments consumers consider most important, and whether and how these payment characteristics affect consumers' payment behavior.

We find that improved payment speed would slightly increase the adoption of several payment methods, while security enhancements would be more likely to increase the use of specific payment instruments. Adoption of Automatic Clearing House (ACH)-based electronic payments-online banking bill payments (OBBP) and bank account number payments $(\mathrm{BANP})^{7}$-is most likely to be influenced by increasing the speed of payments, while debit card and credit card use would increase with improved security in safeguarding financial wealth. We apply these results to simulate two specific policies: improving the speed of ACH-based payments and enhancing the security of payment cards in guarding against risks to financial wealth. We then assess the impact of these policies on consumer behavior. In the welfare analysis presented here, we focus on the benefits rather than the costs, although Greene et al. (2014) shows that the cost of implementing and operating faster payments is likely to be

\footnotetext{
${ }^{5}$ See Schuh and Stavins (2010, 2013), Ching and Hayashi (2010).

${ }^{6}$ See Schuh and Stavins (2014) for a more complete description of the SCPC survey in 2011-2012.

${ }^{7}$ Online banking bill payment (OBBP) is a payment made from a bank's online banking website or online mobile app that accesses funds from a customer's checking or savings account to pay a bill or to pay other people. Bank account number payment (BANP) is a payment made by providing one's bank account number to a third party, such as one's employer or a utility company.
} 
relatively low. On the other hand, the cost of increased card security, such as by broad adoption of the EMV (Europay, MasterCard, and Visa) standard would likely be much higher.

Although speed and security are statistically significant determinants of consumer payment choice, the likely effects of these characteristics on consumers is not economically significant. Instead, other attributes of payments - convenience, cost, and record keeping-have greater effects on consumer payment behavior. Our analysis focuses only on consumers and does not include any potential benefits to merchants, businesses, or financial institutions. If improved speed or security helped financial institutions reduce their costs, it is possible that consumers might benefit indirectly from such enhancements. We analyze the potential effects of speed and security improvements on consumer welfare through changes in consumer payment behavior. It is possible that consumer welfare might increase even if the improvements had little effect on consumer payment adoption or use, as we discuss in our concluding section.

\section{FRFS Findings on Speed and Security}

\section{A. Speed}

The FRFS conducted market research to solicit end users' preferences and views on the importance of various payment features, including the speed of payment deduction, the speed of payment notification, and the confirmation of recipients' receipt of funds. The research combined small focus groups and a set of questions administered to a larger sample of consumers. The FRFS used a "discrete choice methodology" for evaluating attribute importance and consumer preferences. The questions included a set of specific real-life cases, where respondents were given a description of the type of payment and how long it would take to process a payment using various payment methods. Respondents were asked to choose a payment based on the description.

A summary of the FRFS findings related to speed reveals the following: ${ }^{8}$

\footnotetext{
${ }^{8}$ http://fedpaymentsimprovement.org/wp-content/uploads/enduser demand summary.pdf
} 
- Respondents indicated that the speed of payment deduction is more important than the speed of a recipient's receiving payment;

- When presented with a choice of faster or slower payment deduction, 69 percent of consumers indicated a preference for faster payment deduction;

- 75 percent of consumers stated that timely payment notification is important.

Although the FRFS research found that payment speed is important to consumers, it is not the most important factor, a finding confirmed in the SCPC survey. The FRFS quantitative results on the extent to which improving payment speed would change consumer behavior were limited and have not been published. The research did not provide a comprehensive analysis of consumer adoption or use. It was based on hypothetical situations rather than on revealed preference.

\section{B. Security}

The FRFS conducted the Payment Security Landscape Study ${ }^{9}$ to understand end-to-end security needs. Although security enhancement was identified as a priority, there was no focus on any specific aspects, because the goal includes preventing any potential future threats. However, the protection of data was specifically mentioned.

\section{Measuring the Speed and Security of Payment Instruments}

Each year, the SCPC questionnaire asks its respondents to evaluate payment instruments according to a set of payment attributes (see Table 1 for a list of attributes included in each annual survey). Speed was included only in the initial SCPC in 2008, and the question asked consumers only to evaluate each payment instrument with respect to speed time at checkout. Because the assessment of speed time at checkout was found not to affect payment adoption and only weakly to affect the use of checks and prepaid cards (Schuh and Stavins 2013), the question about speed was dropped from subsequent versions of the SCPC.

\footnotetext{
${ }^{9}$ http://fedpaymentsimprovement.org/wp-content/uploads/payment security landscape.pdf
} 
In each annual SCPC between 2008 and 2012, consumers ranked security as the most important characteristic of payments. Security was also found to affect the adoption and use of some payment instruments (Stavins 2013). However, the security question included both possible financial loss and a loss of privacy. Based on the responses to the single security question, it is difficult to figure out which aspect of security matters most to consumers and how enhancing individual features would affect consumer adoption or use of specific payment instruments.

In 2013, we added a set of detailed questions about speed and security in the annual SCPC survey to learn more about consumer preferences related to the FRFS strategic goals. In addition to the standard set of characteristics included in previous annual surveys, we asked about four, speed-related characteristics that match the FRFS speed aspects and three, securityrelated characteristics. Table 2 shows how we mapped the FRFS speed aspects into the SCPC questions. The exact SCPC survey questions are included below in italics.

\section{A. Speed}

The Federal Reserve Financial Services market research identified three aspects of speed:

- Transaction speed: The amount of time it takes to initiate the payment and receive confirmation (if confirmation is normally expected) that the payment has been successfully scheduled. This combines the speed at the time of payment and the speed of receiving notification when the payment leaves the payer's account.

- Availability speed: The amount of time that passes between when a payment is initiated and when funds are credited to the payee's account. This is the speed of the recipient's receipt of the money.

- $\quad$ Posting speed: How quickly the payer's account balance is debited after the payment is initiated. This is the speed with which payments are deducted from the payer's account. 
In order to collect more information about how consumers value these aspects of speed, we selected the speed characteristics to match those included in the FRFS study. The following speed attributes were included in the 2013 Survey of Consumer Payment Choice:

\section{Speed at time of payment}

When you make a payment transaction, the time it takes to start and complete the payment may depend on the choice of payment method. Some payment methods might take less time than others. Please assess the speed of the payment transaction for each payment method.

\section{Speed of payment deduction}

When you make a payment transaction, a period of time may pass before the money is deducted from your bank account or prepaid card. Please assess the speed with which money is deducted from your bank account or prepaid card after you make a payment.

\section{Speed of recipient receiving payment}

When you make a payment transaction, a period of time may pass before the recipient of the payment (the payee) receives the money. Please assess the speed with which the recipient (the payee) gets the money for each payment method.

\section{Speed of notification of balances}

When you make a payment transaction, a period of time may pass before the payment is reported in the balance of your bank account or payment card. Please assess the speed with which you can see an up-todate balance after the payment for each payment method.

\section{B. Security}

Although the FRFS did not list specific aspects of security, we focused on separating financial security from privacy. The former involves a risk of losing money, while the latter involves the risk of one's personal information being obtained by others without the target's consent. We also asked about confidentiality of information (or "anonymity") about the payment transaction itself: 


\section{Security of personally identifiable information}

Suppose a payment method has been stolen, misused, or accessed without the owner's permission. Please rate the security of each method against unwanted disclosure of personal information such as name, address, telephone number, Social Security number, date and place of birth, mother's maiden name, etc.

\section{Security of financial wealth}

Suppose a payment method has been stolen, misused, or accessed without the owner's permission. Please rate the security of each method against permanent financial loss to the owner of the payment method.

\section{Security of information about of payment transactions}

Suppose a payment method has been stolen, misused, or accessed without the owner's permission. Please rate the security of the confidentiality of each method against others finding out what products were purchased, how much was paid, or where the products were bought.

Survey respondents were asked to rate each of the above characteristics on an absolute scale of 1 to 5 for each payment instrument, where 1 was the least desirable (slowest or least secure) and 5 was the most desirable (fastest or most secure). In general, a lower rating for a particular payment method meant that a consumer considered that payment method to be inferior with respect to a given characteristic. Note that the numeric values represent qualitative ranking and do not reflect actual quantitative measures like time (seconds, minutes, days) or comprehensive details of actual measures (such as all aspects of cost). However, in theory and practice, consumers' ratings of the characteristics should be positively correlated with all of the actual characteristics. In previous research (Schuh and Stavins 2010, 2013) we found that consumer payment behavior is strongly influenced by relative characteristics, which measure a consumer's rating of a given payment method relative to all the other payment methods. For example, a consumer may rate the speed of credit cards at the time of payment as 4 , but the speed of debit cards as 5 . Although 4 is a high rating, that consumer may choose to use his debit card instead. Using relative ratings in the model allows us to measure how each of the characteristics influences which payment methods consumers adopt and use, and why they do so. Although some payment behavior is correlated with demographic attributes - for example, younger people are more likely to use debit cards, while older people are more likely to use 
checks-we found that a substantial amount of variation in payment behavior among consumers remains unexplained even when controlling for several demographic and financial variables. Incorporating payment characteristics allows us to explain some of the differences in how people pay.

Figures 1 and 2 show the numeric ratings for the speed and security characteristics, based on the 2013 SCPC survey. As the figures show, the ratings vary across the payment instruments and across the various aspects of speed or security. For example, cash is rated very low in terms of financial security, but very high in terms of the security of personal information. However, there are a few visible patterns. Several of the speed ratings in Figure 1 are mostly blue, while the security ratings in Figure 2 have less blue and more red, indicating that consumers tend to be more satisfied with the speed of payments than they are with the security of payments. Speed time at checkout was rated especially high-consistent with the FRFS findings. Speed time at checkout was also rated by consumers as more important than the other three aspects of speed.

\section{Comparing the FRFS with the SCPC: Objective, Methodology, and Findings}

Although the Federal Reserve's strategic plan pertains to all parties-consumers, businesses, and financial institutions - and is aimed at increasing social welfare, our analysis focuses on consumers' welfare only. This perspective is an important input to the overall analysis because the strategic plan is increasing the weight on "end-user preferences," where end users include consumers and businesses. Ultimately, maximizing consumers' utility is the primary objective. It is also the aspect about which we know least.

Our methodology differs from the FRFS approach. In the focus group part of the FRFS analysis, a small group of consumers were asked which aspects of speed were important (see the summary of those results above). In the quantitative part of the analysis, the FRFS commissioned a market research study to solicit consumer preferences related to the speed of 
payments based on hypothetical scenarios relying on the consumers' stated preferences. ${ }^{10}$ In contrast, we use actual adoption and use of all payment methods, or revealed preference, and every consumer's rating of each aspect of speed and security characteristic, to estimate an econometric model of the adoption and use of each payment method. The econometric model allows us to assess separately the impact of each characteristic, while controlling for each consumer's demographic and income attributes as well as the consumer's assessments of all the other characteristics. The SCPC analysis complements the FRFS analysis by studying characteristics specifically designed to match the Federal Reserve strategic objectives, but employs a methodology that goes beyond that applied in the FRFS market research.

Although the FRFS survey asked its respondents to rate various aspects of speed, we cannot directly compare the FRFS findings with those based on the SCPC survey, because they used different methods and metrics. The FRFS survey did not estimate the effect of speed improvements on consumer payment behavior. For example, 69 percent of FRFS respondents indicated that they prefer faster rather than slower payment deduction and 75 percent stated that timely payment notification is important, whereas while the SCPC respondents consider the speed of payment deduction to be more important than the speed of payment notification, the main contribution of the SCPC study is in estimating how improvements in either aspect of speed might influence the way consumers actually pay. ${ }^{11}$

In the SCPC, consumers considered the security of payment methods more important than speed. When respondents were asked to rank the importance of the seven speed and security attributes of payments methods, all three aspects of security were ranked higher than any of the speed-related attributes (Table 3). Among the security characteristics, the security of financial wealth was ranked the highest, with 56 percent of respondents ranking it the most important of the seven. Among the speed characteristics, speed at the time of payment was ranked the highest (but below all the security measures), and the speed of the recipient's receipt

\footnotetext{
10 The study used a discrete choice methodology. The speed choices were embedded within the context of other situational variables to enhance the realism of the experiment. See the appendix for a more extensive description of that part of the study.

11 The FRFS study also did not collect data on individual consumers' actual adoption and use of all payment instruments in various contexts.
} 
of payment was ranked the lowest. Previous versions of the SCPC included a combined security attribute, and it was consistently ranked as the most important characteristic (except in 2013, when it ranked as the second most important). Speed time at checkout was included only in 2008, when it ranked second-to-last in importance (Table 4).

\section{Effects of Speed and Security on Payment Behavior}

We estimate adoption and use of each payment instrument, where use is defined as the share of transactions conducted with each payment instrument. In our two-stage model, consumers first adopt a portfolio of payment instruments, such as debit, credit, cash, and check. Adoption of payment methods is stage one and a prerequisite to use. Then, consumers choose how extensively to use each instrument. That is, consumers first decide which instruments to adopt, and then decide which of the ones they have adopted to use. We therefore estimate separately the effect of the explanatory variables on adoption, and then on use, conditional on adoption. We apply the Heckman (1976) selection model, which controls for potential selection bias in payment use. ${ }^{12}$

We include a set of payment method characteristics described above in the adoption and use regressions. Although we focus on speed and security in this brief, other attributes might be more important in influencing payment behavior. Setup, convenience, cost, and record keeping were all highly statistically significant factors affecting payment method adoption. (Appendix Table 1 defines each characteristic used in the survey.) Convenience was the factor that affected the use of almost all payment methods most strongly. Table 5 shows which aspects of security and speed were statistically significant in the adoption and use regressions, while Appendix Tables 2 and 3 show the full regression results for adoption and use, respectively.

\section{A. Speed}

The results show that certain aspects of speed statistically significantly influence the adoption of selected payment instruments, especially speed at the time of payment and speed of payment

\footnotetext{
12 See Schuh and Stavins (2010) for a more detailed description of this model.
} 
deduction. In particular, improving both aspects of speed would lead to higher adoption of ACH-based payments, namely OBBP and BANP. Adoption of checks and credit cards was not affected significantly by any form of speed.

Conditional on adoption, only speed time at checkout is statistically significant in influencing the use of payment instruments, and only checks and the two ACH-based payment methods are significantly affected. However, this aspect of speed is not included in the Federal Reserve strategic plan, and the scope for improvements in consumer welfare is small, because the time at checkout is already short and is unlikely to be affected by the Federal Reserve's policy. No other aspect of speed had a significant effect on payment use. The use of cash, debit cards, credit cards, or money orders was not significantly affected by any aspect of speed.

\section{B. Security}

Despite the ranking of security as the most important payment characteristic, security had only a modest effect on payment adoption or use. Security of financial wealth was the most statistically significant determinant of credit card and debit card use, indicating that consumers who rate credit and debit card security of financial wealth low relative to other payment instruments are significantly less likely to use them. Enhancing financial security could therefore help to increase credit card and debit card use among cardholders. Note that cards can be used in person, online, or on mobile devices, and that card use may occur through the use of payment services such as PayPal. Although card security may vary depending on location and/or device, our data do not allow us to estimate separate effects of security by location.

Security of personal information was the most significant determinant of OBBP adoption, both statistically and economically. This finding is consistent with the consumers' assessment of security of payments by location: consumers rated payments made in person or by mail as more secure than those made using the internet, and consumers rated payments made using mobile phones least secure. It is not surprising, therefore, that high assessments of security of personal information correspond with high adoption rates of OBBP. Although consumers' security rating of OBBP had a significant influence on their adoption of OBBP, 
OBBP was rated more secure than BANP. In the use stage, security of personal information had a small effect on the use of payment methods directly linked to bank accounts: checks, OBBP, and BANP. Security of payment transaction information (anonymity of purchases) was not significant in any payment adoption or use regressions. ${ }^{13}$ This result is surprising for cash, which is alleged to be valued for its privacy and anonymity with respect to payment transactions.

\section{Payment Theft and Identity Theft Experience}

In addition to questions about the security assessment of individual payment instruments, the SCPC asked respondents whether or not they had experienced a lost or stolen payment instrument, and if so, whether they had suffered any monetary loss resulting from that experience. Although experiencing any lost or stolen payment instrument had a very small negative effect on the use of checks and BANP, those effects were only weakly statistically significant. Including the theft dummy variable did not change the coefficients on the security variables.

Turning to the issue of identity theft, we compared security ratings among groups of respondents with direct, indirect, or no experience with identity theft and found very little variation in average security ratings. In particular, respondents with no identity theft experience did not rate the security of payment methods any higher than those who either had experienced identity theft themselves or knew someone who had experienced it. To test whether experiencing identity theft influences consumers' adoption or use of individual payment methods, we included the variable in the regressions. Experiencing identity theft and/or knowing a person who had experienced it had almost no significant effect on the adoption or use of payment methods. The only exception was a negative and significant effect on the use of BANP from having directly experienced identity theft. Moreover, including those variables in the model did not change the overall effect of security on payment behavior.

\footnotetext{
${ }^{13}$ The results might vary by type of payment. In future research, we plan to explore the differences between bill and nonbill payments.
} 
We also followed the methodology in Kahn and Liñares-Zegarra (2013), who examined the effect of having experienced identity theft on the adoption and use of payment instruments using data from the 2009 SCPC survey. Here, we apply their methodology using the 2013 data: we estimate the adoption and use of payment instruments, but we replace the original assessment of security with a measure of security that is uncorrelated with the variable representing the identity theft experience. ${ }^{14}$ This way we can separate the effect of having experienced identity theft from the effect of security assessment on payment behavior. The results are shown in Appendix Tables 4 and 5. As above, identity theft had almost no significant effect on payment behavior, except for a negative and significant effect on the use of BANP of a respondent's having experienced identity theft directly. However, the effect of security on the adoption and use of payments with or without identity theft was similar: consumers who rated security higher were significantly more likely to adopt OBBP and BANP, and to use a significantly higher share of checks and debit cards .

Although identity theft is not explicitly mentioned in the Federal Reserve's strategic plan, preventing identity theft is clearly related to enhancing safety and security of paymentsone of the plan's strategic goals. Nevertheless, the experience of identity theft was found to influence the use of payments only weakly, while security in general was a significant factor, regardless of whether or not consumers had experienced identity theft.

\section{Simulating the Effect on Consumer Payment Behavior of Policies that Enhance Speed and Security}

To better understand the implications of potential improvements in speed or security, we simulated enhancements in speed and security. We use our regression results to assess what would happen if the Federal Reserve undertook policies leading to the following outcomes: faster ACH-based payment systems and more-secure card systems.

For each of these simulations, we assume that all consumers would notice the improvement and that therefore all consumers would increase their rating of the payment

\footnotetext{
${ }^{14}$ For more information on this method, see Kahn and Liñares-Zegarra (2013).
} 
methods in question. In reality, it is obviously more likely that an improvement would affect some consumers more than others, and that many consumers might not even be aware of a change. Therefore, our assumptions should be considered optimistic, and the resulting changes in consumer payment behavior should be treated as an upper bound of what would be observed in reality.

\section{A. Faster-Speed ACH-Based Payment Systems}

The first speed-related strategy on the FRFS proposed list is to "Evolve ACH." We assume that the strategy would lead to faster payment deduction and notification for ACH-based payments, namely, for OBBP and BANP. This simulation also has implications for a potential new payment service, such as the U.K. Faster Payment Service, which has some of the same functionality as ACH. ${ }^{15}$

Consumers who rate the speed of payment deduction high for $\mathrm{ACH}$-based payment methods-OBBP and BANP-have a significantly higher adoption rate of those payments. We assume that the relative rating of the speed of payment deduction for OBBP and BANP increases by 10 percent and measure how such a rating increase would change the adoption of those two payment instruments. We use a 10 percent increase, but the effect is linear, so it can be applied to any increase in speed. Recall that these ratings do not represent any real numbers, and translating a percentage increase in speed rating to a real-life situation is not straightforward. Because the FRFS market research study found that "end users ... feel that their needs [regarding the speed of payments] are usually being met" (qualitative research, Phoenix International), even a 10 percent increase in speed rating might require a substantial improvement in the actual speed. Although we find that the adoption of both ACH payments would increase, the resulting increase is very small: the adoption of BANP would increase by 0.37 percentage point, from 66.2 percent to 66.6 percent, and the adoption of OBBP would increase by 0.43 percentage point, from 56.6 percent to 57.0 percent of consumers. Converting these results to elasticities, a 10 percent increase in the speed of deduction leads to a 0.62 percent

\footnotetext{
${ }^{15}$ See Greene, et al. (2014) for an analysis of the U.K. Faster Payment Service.
} 
increase in the probability of adoption of BANP and a 0.57 percent increase in the probability of adoption of OBBP, yielding estimated elasticities of adoption with respect to improvements in the speed of deduction of 0.062 and 0.057, respectively (Table 6 shows the results of this simulation).

\section{B. More-Secure Card Systems}

One of the FRFS proposed strategies is to "Work with payment system stakeholders to accelerate development and adoption of payment security standards and related business processes." Credit card and debit card use is higher for consumers who consider those payments more secure. One potential security standard adopted in other developed countries is the EMV chip card standard. The EMV chip technology has been recognized to improve security against fraud, as compared with the magnetic stripe card technology widely used in the United States. ${ }^{16}$

We simulate an improvement in the security of financial wealth, which could be created by an introduction of EMV. As in the speed simulation above, we assume that each consumer's relative rating of the security of financial wealth for credit cards and for debit cards increases by 10 percent, but translating an increase in security rating to a real-life situation is not straightforward. In fact quantifying security improvements is even more complex than quantifying changes in speed, which can be measured in units of time. The resulting increase in use is very small: the estimated share of credit card transactions increases by 0.22 percentage points, and the estimated share of debit card transactions increases by 0.16 percentage points. The estimated elasticities of payment card use with respect to improvements in the security of financial wealth are 0.039 for debit cards and 0.084 for credit cards (Table 7 shows the results of this simulation).

\footnotetext{
${ }^{16}$ For example, the transition from magnetic stripe to EMV ("Chip and PIN") in the United Kingdom reduced pointof-sale (POS) card fraud from $£ 219$ million in 2004 to $£ 72$ million in 2006 . The steep decline was partly due to the rapid transition of the entire system - terminals, ATMs, and cards - that took place between October 2003 and February 2006. In terms of percentage of spending, internet fraud declined by more than POS fraud, although the decline was smaller in terms of absolute value (Javelin Strategy \& Research 2014).
} 


\section{Conclusion}

The Financial Services strategic plan lists speed and security of payments as important strategic initiatives for the next few years. However, the Federal Reserve Financial Services market research shows that consumers seem to be satisfied with the current speed of payments. ${ }^{17}$ And even though payment security is important to consumers, we find that improving either speed or security of payments is unlikely to change consumers' payment behavior significantly.

Consumer payment adoption and use are influenced by consumers' perceptions of payment methods. We find that faster $\mathrm{ACH}$ payments would induce consumers to adopt $\mathrm{ACH}$ based payments, and that more secure credit cards and/or debit cards would raise consumers' use of those instruments, but that the resulting changes would most likely be very small, at least in the short run. Consumers' adoption and use of payment instruments is highly inelastic with respect to changes in speed or security. This means that very large improvements in either speed or security would be needed to generate a noticeable increase in the adoption or use of these payment instruments. We simulated faster $\mathrm{ACH}$-based payments and more secure card payments. The former were estimated to significantly increase the adoption of OBBP and BANP, while the latter were estimated to significantly increase the use of credit and debit cards. Nevertheless, the estimated elasticities were all below 0.1 .

Although we cannot specify the exact cost of these innovations, it is very unlikely that such enhancements would increase consumer welfare, at least in the short run. However, we estimated only the effect on consumers as payers and did not include any potential effects on consumers as payees, on merchants, or on financial institutions. For example, the market research commissioned by the FRFS shows that large businesses in particular value fast notification and fund availability, and therefore the benefits to merchants from faster $\mathrm{ACH}$ might outweigh the cost. Faster transaction notification might bring some benefits for consumers whose liquidity is very limited, even if their payment choices remain unchanged. 17 There were some notable exceptions: faster bill payments were important for some consumers, and faster
notification was important for consumers who monitor their (near-zero) balances online. 
For security improvements, a reduction in payment card fraud losses to banks and merchants would reduce the overall payment system cost, possibly leading to lower retail prices for consumers. It is possible that the overall social benefits are higher than the total cost of any proposed enhancements and that therefore total social welfare might increase as a result. In addition, preventing security breaches might preserve public confidence in the payment system, benefitting consumers even if it does not change consumers' payment choices.

Our results complement the earlier FRFS findings, as we quantify the effect of speed or security improvements on the adoption or use of individual payment instruments by consumers. Although the new FRFS strategic plan focuses on speed and security, other attributes of payments have a greater influence on consumer behavior. 


\section{References}

Ching, Andrew and Fumiko Hayashi. 2010. "Payment Card Rewards Programs and Consumer Payment Choice." Journal of Banking and Finance. 34(8): 1773-1787.

Greene, Claire, et al. 2014. "Costs and Benefits of Building Faster Payment Systems: The U.K. Experience and Implications for the United States," Federal Reserve Bank of Boston Current Policy Perspectives No. 14-5.

Javelin Strategy \& Research. 2014. Fixing CNP Fraud: Solutions for a Pre- and Post-EMVU.S. Market, October.

Kahn, Charles M. and José M. Liñares-Zegarra. 2013. “Identity Theft and Consumer Payment Choice: Does Security Really Matter?" SSRN Working Paper.

Schuh, Scott and Joanna Stavins. 2010. "Why Are (Some) Consumers (Finally) Writing Fewer Checks? The Role of Payment Characteristics." Journal of Banking and Finance. 34(8): 1745-1758.

Schuh, Scott, and Joanna Stavins. 2013. "How Consumers Pay: Adoption and Use of Payments," Accounting and Finance Research, 2(2).

Schuh, Scott, and Joanna Stavins. 2014. “The 2011 and 2012 Surveys of Consumer Payment Choice," Federal Reserve Bank of Boston Research Data Report No. 14-1. 
Table 1: Payment Characteristics Included in Annual SCPC Surveys

\begin{tabular}{|l|c|c|c|c|c|c|}
\hline & 2008 & 2009 & 2010 & 2011 & 2012 & 2013 \\
\hline Acceptance & $\checkmark$ & $\checkmark$ & $\checkmark$ & $\checkmark$ & $\checkmark$ & $\checkmark$ \\
\hline Speed & $\checkmark$ & & & & & \\
\hline Security & $\checkmark$ & $\checkmark$ & $\checkmark$ & $\checkmark$ & $\checkmark$ & $\checkmark$ \\
\hline Cost & $\checkmark$ & $\checkmark$ & $\checkmark$ & $\checkmark$ & $\checkmark$ & $\checkmark$ \\
\hline Convenience & $\checkmark$ & $\checkmark$ & $\checkmark$ & $\checkmark$ & $\checkmark$ & $\checkmark$ \\
\hline Record keeping & $\checkmark$ & & $\checkmark$ & $\checkmark$ & $\checkmark$ & $\checkmark$ \\
\hline Control over timing & $\checkmark$ & & & & & \\
\hline Setup & $\checkmark$ & & $\checkmark$ & $\checkmark$ & $\checkmark$ & $\checkmark$ \\
\hline
\end{tabular}

Table 2: Comparison between FRFS and SCPC: Aspects of Speed

\begin{tabular}{|l|l|}
\hline \multicolumn{1}{|c|}{ FRFS } & \multicolumn{1}{c|}{ SCPC } \\
\hline \multirow{2}{*}{ Transaction speed } & Speed at time of payment \\
\cline { 2 - 2 } & Speed of notification of balances \\
\hline Availability speed & Speed of recipient receiving payment \\
\hline Posting speed & Speed of payment deduction \\
\hline
\end{tabular}

Source: FRFS: End User Research Report; SCPC: 2013 Survey of Consumer Payment Choice 
Table 3: Ranking of Speed and Security Characteristics

\begin{tabular}{|cl|c|c|}
\hline Ranking & \multicolumn{1}{c|}{ Characteristic } & $\begin{array}{c}\text { Least Important } \\
\text { (\% consumers) }\end{array}$ & $\begin{array}{c}\text { Most Important } \\
\text { (\% consumers) }\end{array}$ \\
\hline $\mathbf{1}$ & Security of financial wealth & 2.5 & 37.4 \\
$\mathbf{2}$ & Security of personally identifiable information & 4.3 & 20.3 \\
$\mathbf{3}$ & Security of information about payment transactions & 9.1 & 13.2 \\
$\mathbf{4}$ & Speed at time of payment & 17.0 & 8.7 \\
$\mathbf{5}$ & Speed of payment deduction & 18.7 & 7.3 \\
$\mathbf{6}$ & Speed of notification of balances & 16.6 & 6.7 \\
$\mathbf{7}$ & Speed of recipient receiving payment & 31.8 & 6.4 \\
\hline
\end{tabular}

Source: Survey of Consumer Payment Choice 2013.

Note: The numbers show percent of respondents who rated each characteristic as "Least important" and

“Most important." Each column adds up to 100.

Table 4: Ranking of All Characteristics in Annual SCPC Surveys

\begin{tabular}{|l|cccccc|}
\hline \multirow{2}{*}{ Characteristics } & \multicolumn{7}{|c|}{ SCPC survey year } \\
\cline { 2 - 6 } & $\mathbf{2 0 0 8}$ & $\mathbf{2 0 0 9}$ & $\mathbf{2 0 1 0}$ & $\mathbf{2 0 1 1}$ & $\mathbf{2 0 1 2}$ & $\mathbf{2 0 1 3}$ \\
\hline Security & 1 & 1 & 1 & 1 & 1 & 2 \\
Convenience/ Ease of use & 2 & 2 & 2 & 2 & 2 & 1 \\
Cost & 4 & 3 & 3 & 3 & 3 & 3 \\
Acceptance & 5 & 4 & 4 & 4 & 4 & 4 \\
Payment records & 6 & $n a$ & 5 & 5 & 5 & 5 \\
Acquisition \& set up & 8 & $n a$ & 6 & 6 & 6 & 6 \\
Control of payment timing & 3 & $n a$ & $n a$ & $n a$ & $n a$ & $n a$ \\
Payment speed & 7 & $n a$ & $n a$ & $n a$ & $n a$ & $n a$ \\
\hline
\end{tabular}

Source: Survey of Consumer Payment Choice 2008-2013. 
Table 5: Payment Method Adoption (top panel) and Use (bottom panel) Regressions: Statistically Significant Characteristics

\begin{tabular}{|c|c|c|c|c|c|c|c|c|}
\hline \multirow{6}{*}{$\begin{array}{l}\text { Adoption } \\
\text { Acceptance } \\
\text { Cost } \\
\text { Convenience } \\
\text { Set up } \\
\text { Records } \\
\end{array}$} & Cash & Check & Debit & Credit & Prepaid & OBBP & BANP & Mon \\
\hline & $n a$ & & & & & & & \\
\hline & $n a$ & & & & & & & \\
\hline & $n a$ & & & & & & & \\
\hline & $n a$ & & & & & & & \\
\hline & $n a$ & & & & & & & \\
\hline \multirow{4}{*}{$\begin{array}{l}\text { Speed at time of payment } \\
\text { Speed of payment deduction } \\
\text { Speed of notification of balances } \\
\text { Speed of recipient receiving pavment }\end{array}$} & $n a$ & & & & & & & \\
\hline & $n a$ & & & & & & & \\
\hline & $n a$ & & & & & & & \\
\hline & $n a$ & & & & & & & \\
\hline \multirow{3}{*}{$\begin{array}{l}\text { Security of financial wealth } \\
\text { Security of personally identifiable information } \\
\text { Security of information about transactions }\end{array}$} & $n a$ & & & & & & & \\
\hline & $n a$ & & & & & & & \\
\hline & $n a$ & & & & & & & \\
\hline$\underline{\text { Use }}$ & Cash & Check & Debit & Credit & Prepaid & OBBP & BANP & Mon \\
\hline \multicolumn{9}{|l|}{$\overline{\text { Cost }}$} \\
\hline \multicolumn{9}{|l|}{ Convenience } \\
\hline \multicolumn{9}{|l|}{ Records } \\
\hline \multicolumn{9}{|l|}{ Speed at time of payment } \\
\hline \multicolumn{9}{|l|}{ Speed of payment deduction } \\
\hline \multirow{2}{*}{\multicolumn{9}{|c|}{$\begin{array}{l}\text { Speed of notification of balances } \\
\text { Speed of recipient receiving payment }\end{array}$}} \\
\hline & & & & & & & & \\
\hline \multicolumn{9}{|l|}{ Security of financial wealth } \\
\hline \multirow{2}{*}{\multicolumn{9}{|c|}{$\begin{array}{l}\text { Security of personally identifiable information } \\
\text { Security of information about transactions }\end{array}$}} \\
\hline & & & & & & & & \\
\hline
\end{tabular}

Source: Survey of Consumer Payment Choice 2013. Blue colors mean statistically significant coefficients. Pale blue means that the coefficient is below 0.05 , medium blue means that the coefficient is between 0.05 and 0.1 , and dark blue means that the coefficient is greater than 0.1 . 
Table 6: Simulation Results of Increasing Speed of Notification and Deduction

Rating by $10 \%$ and $50 \%$

\begin{tabular}{ccc}
\hline \hline Description & OBBP & BANP \\
\hline Adoption, Percentage of Consumers & 54.99 & 63.06 \\
Model Prediction, Adoption [Baseline] & 56.60 & 66.24 \\
& Difference: Simulation - Baseline \\
\cline { 2 - 3 } Speed (Increase 10\%) & & 0.43 \\
Increase Both Speed of Deduction and Speed of Notifcation & 0.32 & 0.37 \\
Increase Speed of Deduction & 0.11 & -0.04 \\
Increase Speed of Notification & & 1.79 \\
& & 2.01 \\
Speed (Increase 50\%) & 2.11 & -0.22 \\
Increase Both Speed of Deduction and Speed of Notifcation & 1.56 & 0.56 \\
Increase Speed of Deduction & & Elasticity \\
Increase Speed of Notification & & 0.056 \\
Speed (Increase 10\%) & & 0.062 \\
Increase Both Speed of Deduction and Speed of Notifcation & 0.076 & -0.006 \\
\hline Increase Speed of Deduction & 0.057 & 0.019 \\
Increase Speed of Notification & &
\end{tabular}

Table 7: Simulation Results of Increasing Security Rating by $10 \%$ and $50 \%$

\begin{tabular}{ccc}
\hline Description & Debit & Credit \\
\hline Percent Share of Use, All Consumers & 28.63 & 19.49 \\
Model Prediction, Share of Use [Baseline] & 40.52 & 26.23 \\
Security (Increase 10\%) & Difference: Simulation - Baseline \\
\cline { 2 - 3 } Increase All Components of Security & & \\
Increase Security of Wealth & 0.16 & 0.10 \\
Increase Security of Personally Identifiable Information & 0.16 & 0.22 \\
Increase Security of Confidential Information & 0.02 & -0.04 \\
\end{tabular}

\section{Security (Increase 50\%)}

Increase All Components of Security

Increase Security of Wealth

Increase Security of Personally Identifiable Information

Increase Security of Confidential Information

$\begin{array}{rr}0.82 & 0.51 \\ 0.82 & 1.10 \\ 0.10 & -0.20 \\ -0.11 & -0.39\end{array}$

Elasticity

\section{Security (Increase 10\%)}

Increase All Components of Security

0.039

0.038

Increase Security of Wealth

0.039

0.084

Increase Security of Personally Identifiable Information

0.005

$-0.015$

Increase Security of Confidential Information

$-0.030$ 
Figure 1: Rating of payment instrument speed

Speed Time at Checkout

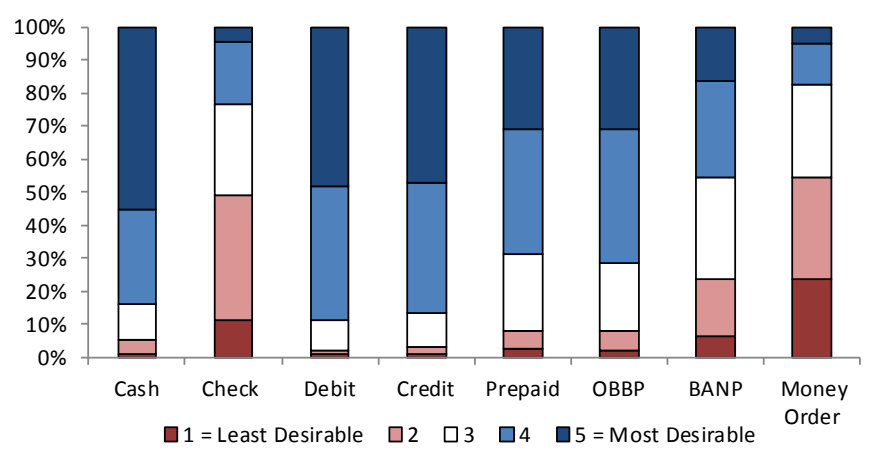

Speed, Deduction

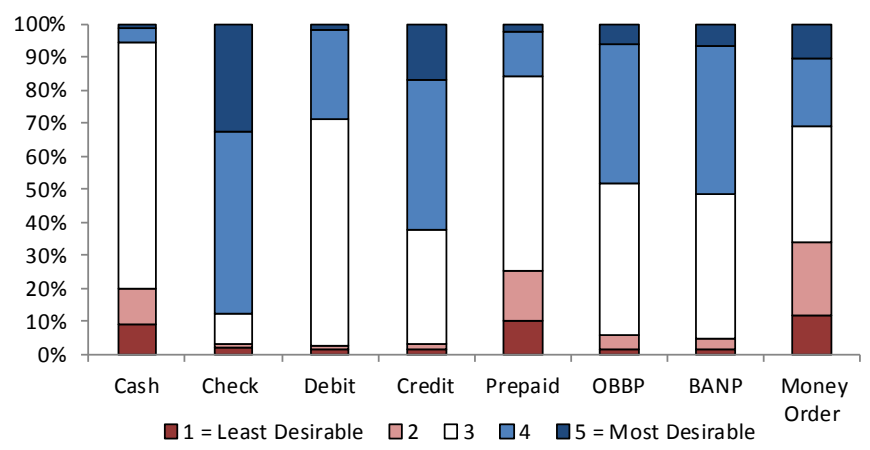

Speed, Notification

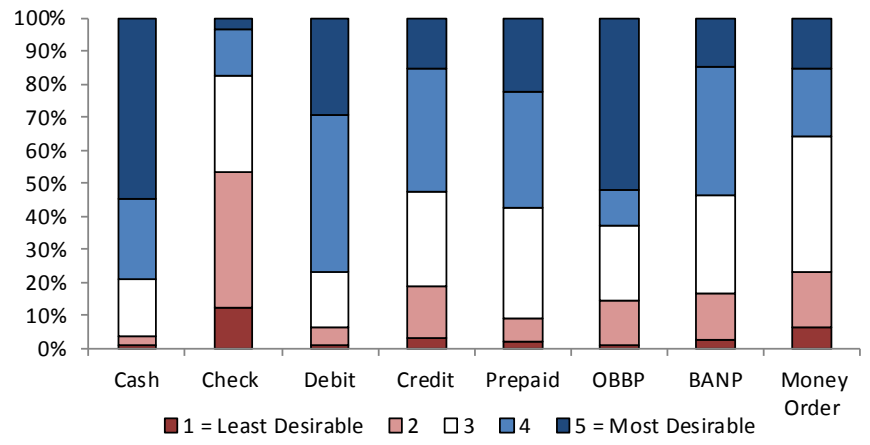

Speed, Receipt

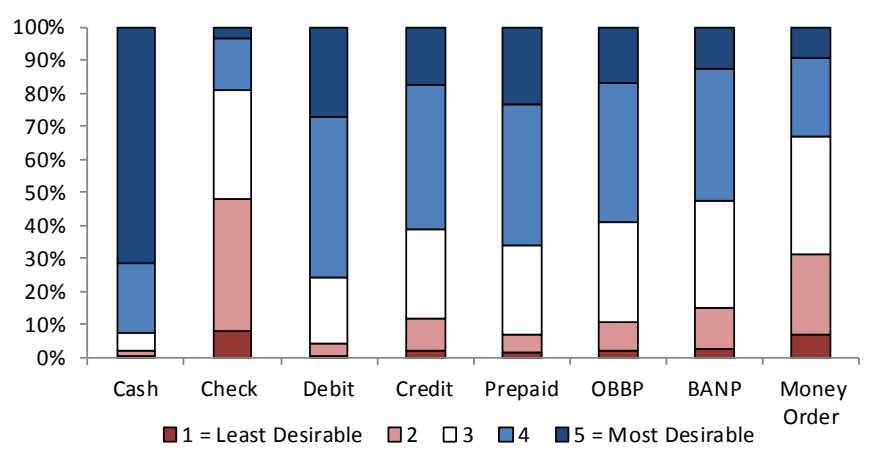

Source: 2013 SCPC

Note: OBBP refers to online banking bill payment; BANP refers to bank account number payment 
Figure 2: Rating of payment instrument security
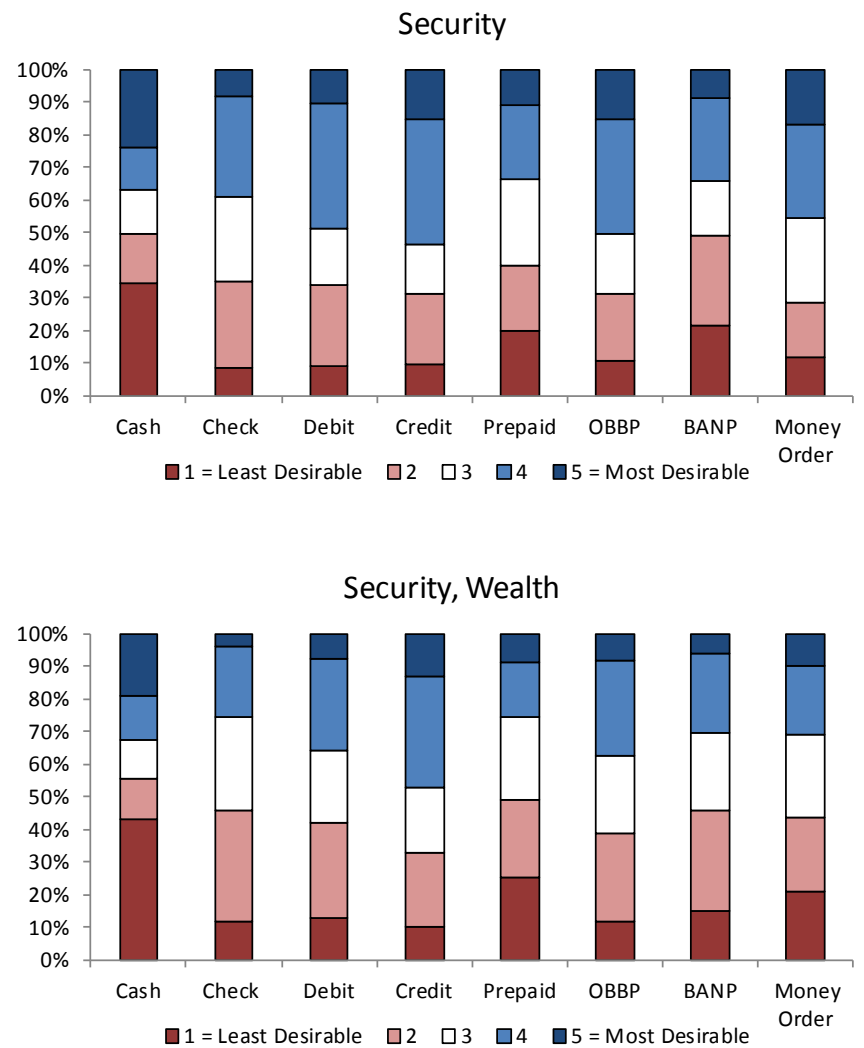

Security, Personally Identifiable Information

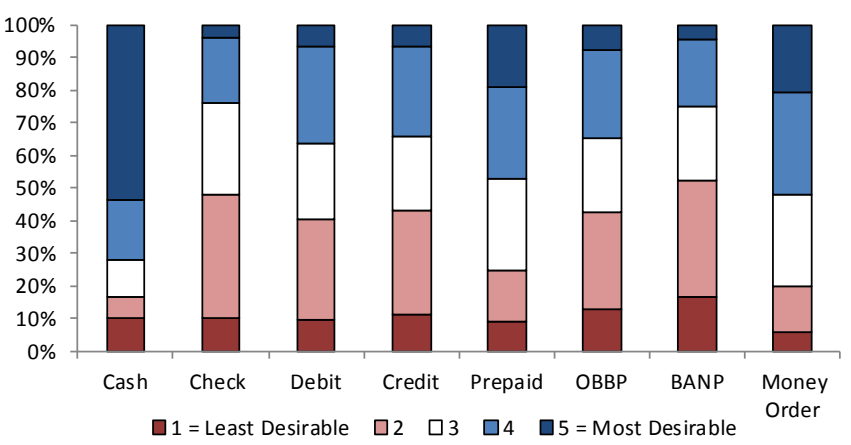

Security, Confidentiality

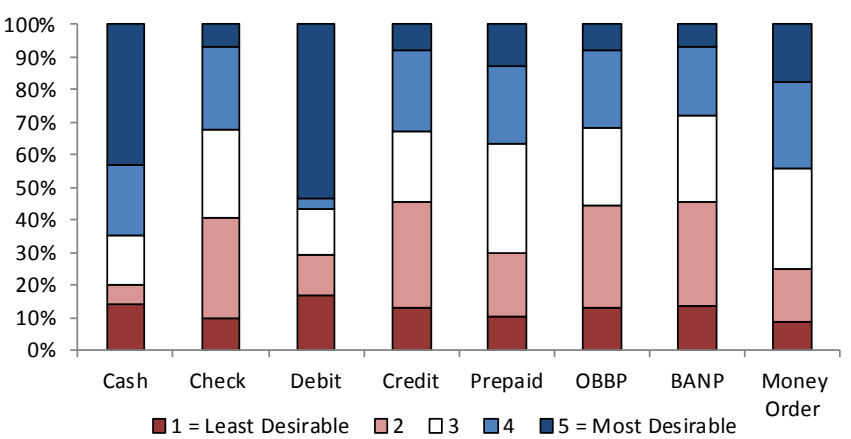

Source: 2013 SCPC

Note: OBBP refers to online banking bill payment; BANP refers to bank account number payment 


\section{Appendix: Comparing the SCPC and the Phoenix Faster Payments Research study}

As part of the Faster Payments Research project, the Federal Reserve's Future Payments Team (FPT) commissioned Phoenix Marketing International (Phoenix) to survey consumers' preferences and attitudes concerning the speed of payments,. The aspects of speed considered by the FPT are speed of deduction from the account, speed with which the recipient gets the money, and the speed with which a valid payment is confirmed. Respondents were presented with various payment scenarios and asked to choose between four payment options in which different combinations of the three speed characteristics were assigned to different payment instruments. For each scenario, Phoenix specified a payment method and dollar value of the transaction. Based on the respondents' selections, Phoenix determined these consumers' preferences concerning payment speed.

The main difference between the SCPC and the Phoenix approach is that the SCPC collects revealed preference data, while Phoenix collects stated preference data. In other words, the SCPC collects data on which payment instruments consumers actually have and how they pay, while Phoenix collected data on what consumers said they would do in a hypothetical situation. Economists and other social scientists prefer to work with revealed preference data, because it is considered less likely to be biased.

The advantage of Phoenix's approach is the variety of the scenarios presented. The scenarios included point-of-sale transactions, bill payments, and person-to-person payments, and differentiated the dollar amount of transactions by payment method. However, drawing conclusions based on the results of these scenarios might be problematic. The main issue is that people may have strong prior assumptions associated with specific payment instruments. If so, they may select a payment method regardless of the degree of speed associated with each scenario. For example, a respondent who likes to write checks may select a check for his bill payment scenario, but it can be difficult to determine whether his selection was due to the speed of debiting funds, of receiving funds, of notification, or for reasons completely unrelated to any aspect of speed. It might be better not to reveal the payment instrument, but only 
provide the respondents with a set of features associated with a given transaction. In addition, because Phoenix does not employ regression analysis, their methodology does not allow for estimating the effect of speed on payment choice separately from any potential effects of demographic or income attributes.

In contrast, the SCPC approach allows respondents to rate various attributes of each payment method separately. A respondent may rate checks high because of their low cost and good record keeping capabilities, but rate checks low because of the long time it takes for the funds to be debited from the account. The SCPC survey asks respondents separately about their payment adoption and use and employs the technique of econometric regression, allowing us to estimate separately the effect of a respondent's rating of each characteristic-including each aspect of speed-on the respondent's payment behavior, while holding demographic and income attributes constant. This way, we not only learn whether a consumer considers each payment method to be desirable or undesirable based on each characteristic, but also are able to estimate the effect of the ratings on the adoption and use of each payment method, while controlling for demographic attributes and income. Our methodology allows us to test whether a low rating of checks because of the slowness with which funds are debited has a negative effect on the use of checks. In many cases, we find that consumer ratings of these characteristics do not significantly affect payment behavior.

Despite the differences in approach, the Phoenix findings are broadly in agreement with the findings of the SCPC. In particular, payment speed is not the most important attribute to consumers, and most of Phoenix's focus group respondents stated that their needs were met when it comes to payment speed. Phoenix found that "speed components make up 20 percent to 28 percent of importance in selection" of a payment method. Speed was found to be relatively less important for bill payments, and more important for nonbill online and point-of-sale transactions. However, Phoenix did not include "transaction time" (equivalent to speed time at checkout in the SCPC) in their discrete choice model, as they considered it too close to convenience. Among the aspects of speed they did include, payment deduction and notification were relatively important to consumers, whereas the SCPC found that speed time at checkout 
was most important and had the highest effect on payment use. Phoenix results are measured in terms of the percentage of consumers who prefer each speed alternative (for example, instant or one-hour delay), rather than the percentage of consumers who would change their payment behavior if funds deduction or receipt were faster or slower. Based on the percentage of consumers who prefer various payment speed alternatives, it is difficult to predict whether and how they would alter their behavior. 


\section{Appendix Table 1: Payment Instrument Characteristics Definitions}

\begin{tabular}{|l|l|}
\hline \multicolumn{1}{|c|}{ Characteristic } & \multicolumn{1}{|c|}{ Definition } \\
\hline Acceptance for payment & $\begin{array}{l}\text { Please rate how likely each payment method is to be } \\
\text { ACCEPTED for payment by stores, companies, online } \\
\text { merchants, and other people or organizations. }\end{array}$ \\
\hline Convenience & $\begin{array}{l}\text { Please rate the CONVENIENCE of each payment method. } \\
\text { Examples: speed; record } \text { keeping; control over payment } \\
\text { timing; } \text { ease of use; } \text { effort to carry, get or set up; ability to } \\
\text { keep or store. }\end{array}$ \\
\hline Cost & $\begin{array}{l}\text { Please rate the COST of using each payment method. } \\
\text { Examples: fees, penalties, postage, interest paid or lost; } \\
\text { subscriptions or materials raise the cost; cash discounts and } \\
\text { rewards (like frequent flyer miles) reduce the cost. }\end{array}$ \\
\hline Getting \& setting up & $\begin{array}{l}\text { Rate the task of GETTING \& SETTING UP each payment } \\
\text { method before you can use it. } \\
\text { Examples: getting cash at the ATM, length of time to get or set } \\
\text { up, paper work, learning to use or install it, or travel. }\end{array}$ \\
\hline Payment records & $\begin{array}{l}\text { Rate the quality of PAYMENT RECORDS offered by each } \\
\text { method of payment. Consider both paper and electronic } \\
\text { records. } \\
\text { Examples: proof of purchase, account balances, spending } \\
\text { history, usefulness in correcting errors or dispute resolution, } \\
\text { and ease of storage. }\end{array}$ \\
\hline Security & $\begin{array}{l}\text { Suppose a payment method has been stolen, misused, or } \\
\text { accessed without the owner's permission. Rate the } \\
\text { SECURITY of each method against permanent financial loss } \\
\text { or unwanted disclosure of personal information. }\end{array}$ \\
\hline
\end{tabular}




\section{Appendix Table 2: Regression Results for Payment Instrument Adoption}

\begin{tabular}{|c|c|c|c|c|c|c|c|c|c|c|c|c|c|c|c|}
\hline \multirow[t]{2}{*}{ Categories } & \multirow{2}{*}{$\begin{array}{l}\text { Variables } \\
\text { Acceptance }\end{array}$} & \multirow{2}{*}{$\begin{array}{r}\text { Check } \\
.00\end{array}$} & \multicolumn{2}{|r|}{ Debit } & \multicolumn{2}{|r|}{ Credit } & \multicolumn{2}{|r|}{ Prepaid } & \multicolumn{2}{|r|}{ OBBP } & \multicolumn{2}{|r|}{ BANP } & \multicolumn{3}{|c|}{ Money Order } \\
\hline & & & & .07 & $*$ & -.07 & * & .12 & $* * *$ & .06 & & .00 & & .07 & $* * *$ \\
\hline \multirow{11}{*}{ Characterisitcs } & Cost & .02 & $*$ & .10 & $* * *$ & .05 & $* * *$ & -.04 & & .20 & $* * *$ & .12 & $* * *$ & .03 & \\
\hline & Convenience & .01 & & .11 & $* * *$ & .14 & $* * *$ & .00 & & .30 & $* * *$ & .09 & $* * *$ & .07 & $* * *$ \\
\hline & Setup & .05 & $* * *$ & .12 & $* * *$ & .15 & $* * *$ & -.01 & & .17 & $* * *$ & .07 & $*$ & .10 & $* * *$ \\
\hline & Records & .04 & $* * *$ & .09 & $* * *$ & .14 & $* * *$ & -.02 & & .20 & $* * *$ & .08 & $* *$ & .06 & $* *$ \\
\hline & Speed Time at Checkout & .00 & & .19 & $* * *$ & .05 & & .07 & & .14 & $* * *$ & .06 & & .03 & \\
\hline & Speed Deduct & .02 & & .05 & & .01 & & .03 & & .24 & $* * *$ & .27 & $* * *$ & .06 & $* *$ \\
\hline & Speed Notify & .00 & & .04 & & -.03 & & .09 & $*$ & .07 & & -.02 & & .11 & $* * *$ \\
\hline & Speed Receipt & .01 & & .06 & & -.05 & & .04 & & -.21 & $* * *$ & .10 & $* *$ & -.07 & $* *$ \\
\hline & Security Wealth & .01 & & .02 & & .05 & $* *$ & -.05 & $*$ & .07 & $*$ & .05 & & -.02 & \\
\hline & Security PII & -.02 & $*$ & .05 & $*$ & .02 & & .00 & & .15 & $* * *$ & .01 & & .04 & \\
\hline & Security Confidentiality & .01 & & .02 & & .03 & & -.02 & & .02 & & .04 & & .02 & \\
\hline \multirow{5}{*}{ Age } & Under 35 & -.02 & & .05 & & -.07 & & -.10 & & .15 & $* *$ & -.02 & & -.06 & \\
\hline & $25-34$ & -.01 & & .00 & & -.07 & $* *$ & -.02 & & .04 & & .05 & & -.02 & \\
\hline & $45-54$ & .01 & & .02 & & -.01 & & -.08 & $* *$ & -.04 & & .00 & & -.06 & $* *$ \\
\hline & $55-64$ & .03 & $* * *$ & -.01 & & -.01 & & -.08 & $*$ & -.06 & & .01 & & -.03 & \\
\hline & 65 or Over & .03 & $* * *$ & -.03 & & .02 & & -.17 & $* * *$ & -.10 & & -.07 & & -.07 & $*$ \\
\hline \multirow{4}{*}{ Education } & Less than High School & -.06 & & -.29 & $* * *$ & -.20 & $* *$ & -.02 & & -.13 & & -.25 & $* * *$ & -.03 & \\
\hline & High School & -.07 & $* * *$ & -.07 & $* *$ & -.12 & $* * *$ & -.15 & $* * *$ & -.06 & & -.09 & $* *$ & -.04 & \\
\hline & Some College & -.05 & $* * *$ & -.02 & & -.08 & $* * *$ & -.04 & & -.02 & & -.03 & & .03 & \\
\hline & Graduate Degree & .02 & $*$ & -.04 & & .06 & $* *$ & .07 & $*$ & -.02 & & .05 & & .00 & \\
\hline \multirow{4}{*}{ Marital Status } & Never Married & -.02 & * & -.08 & $* *$ & -.07 & $* *$ & .03 & & .00 & & -.10 & $* *$ & .00 & \\
\hline & Separated Divorced & -.05 & $* *$ & -.03 & & -.09 & $* * *$ & .02 & & .02 & & -.03 & & -.03 & \\
\hline & Widowed & .01 & & -.05 & & .01 & & -.08 & & .09 & & .12 & $* *$ & -.03 & \\
\hline & Household Size & .00 & & -.01 & & -.03 & $* * *$ & .01 & & .01 & & .00 & & .00 & \\
\hline Ethnicity & Latino & -.03 & $* *$ & .03 & & -.03 & & .14 & $* * *$ & .05 & & -.01 & & .02 & \\
\hline \multirow{3}{*}{ Race } & Black & -.08 & $* * *$ & .00 & & -.12 & $* * *$ & -.04 & & .02 & & -.04 & & .19 & $* * *$ \\
\hline & Asian & .03 & $* * *$ & .08 & $* *$ & .05 & & .13 & & -.05 & & .11 & & .02 & \\
\hline & Other & -.01 & & -.04 & & -.05 & & -.08 & & .05 & & .00 & & .06 & \\
\hline Gender & Male & -.02 & $*$ & -.02 & & -.03 & & -.08 & $* * *$ & .04 & & -.06 & $* *$ & -.05 & $* *$ \\
\hline & $<\$ 25,000$ & -.18 & $* * *$ & -.14 & $* * *$ & -.18 & *** & .06 & & -.20 & $* * *$ & -.19 & $* * *$ & -.03 & \\
\hline Income & $\$ 25,000-\$ 49,999$ & -.08 & $* * *$ & -.03 & & -.04 & & .00 & & -.03 & & -.05 & & .01 & \\
\hline income & $\$ 75,000-\$ 99,999$ & -.08 & $*$ & -.02 & & .06 & $* *$ & .08 & $*$ & .03 & & -.02 & & -.05 & \\
\hline & $>=\$ 100,000$ & -.04 & & -.03 & & .06 & $* *$ & .14 & $* * *$ & .05 & & -.01 & & .06 & \\
\hline & Not Highest Income In Household & .00 & & .03 & & -.03 & & .00 & & .00 & & .00 & & -.02 & \\
\hline & $<\$ 50,000$ & -.02 & & .04 & & .04 & & -.01 & & -.01 & & .01 & & .09 & $* * *$ \\
\hline & $\$ 50,000-\$ 100,000$ & -.03 & & -.02 & & .03 & & -.06 & & -.01 & & .02 & & .06 & \\
\hline Net Worth & $\$ 250,000$ - \$399,999 & .01 & & -.07 & $*$ & .08 & $* * *$ & .10 & $* *$ & .04 & & -.05 & & .05 & \\
\hline & $>=\$ 500,000$ & .01 & & -.10 & $* * *$ & .04 & & .11 & $* *$ & .02 & & -.01 & & -.02 & \\
\hline & Missing Net Worth & -.03 & & -.09 & & .00 & & .03 & & .04 & & .01 & & .12 & \\
\hline & Retired & .01 & & -.01 & & .05 & * & .01 & & .04 & & -.03 & & -.02 & \\
\hline & Disabled & -.03 & & -.01 & & -.06 & & .29 & $* * *$ & -.03 & & -.09 & & .11 & $* *$ \\
\hline Status & Unemployed & -.04 & $* *$ & -.12 & $* * *$ & -.09 & $* *$ & .07 & & -.05 & & -.09 & $*$ & .02 & \\
\hline & Homemaker & -.05 & & -.10 & $*$ & -.08 & & -.03 & & -.08 & & -.13 & $*$ & -.01 & \\
\hline & Other & -.07 & & -.06 & & -.09 & & .04 & & .03 & & .10 & & .11 & \\
\hline & Pay Bills & .01 & & .01 & & .01 & $*$ & .01 & & .02 & $* *$ & .04 & $* * *$ & .01 & \\
\hline & Shops & .00 & & .01 & & .01 & & .02 & $*$ & .00 & & -.01 & & -.01 & \\
\hline & Born Abroad & .01 & & .02 & & .00 & & -.10 & $* *$ & .03 & & -.04 & & .03 & \\
\hline & Homeowner & .03 & $* *$ & .03 & & .10 & $* * *$ & -.05 & & .07 & $* *$ & .10 & $* * *$ & -.06 & $* *$ \\
\hline & Ever Bankrupt (last 12 months) & -.01 & & -.07 & & .07 & $*$ & .01 & & .00 & & -.16 & & .04 & \\
\hline & Ever Bankrupt (last 7 years) & .00 & & .06 & & -.29 & $* * *$ & .02 & & .04 & & .14 & $* * *$ & .06 & \\
\hline & Number of Observations & 1831 & & 1833 & & 1834 & & 1829 & & 1817 & & 1776 & & 1828 & \\
\hline & R-Squared (CHAR) & .45 & & .28 & & .43 & & .09 & & .24 & & .16 & & .21 & \\
\hline & R-Squared (No CHAR) & .41 & & .14 & & .36 & & .08 & & .10 & & .12 & & .15 & \\
\hline
\end{tabular}




\section{Appendix Table 3: Regression Results for Payment Instrument Use}

\begin{tabular}{|c|c|c|c|c|c|c|c|c|c|c|c|c|c|c|c|c|c|}
\hline \multirow[t]{2}{*}{ Categories } & \multirow{2}{*}{$\begin{array}{l}\text { Variables } \\
\text { Cost }\end{array}$} & \multicolumn{2}{|c|}{ Cash } & \multicolumn{2}{|c|}{ Check } & \multicolumn{2}{|c|}{ Debit } & \multicolumn{2}{|c|}{ Credit } & \multicolumn{2}{|c|}{ Prepaid } & \multicolumn{2}{|c|}{ OBBP } & \multicolumn{2}{|c|}{ BANP } & \multicolumn{2}{|c|}{ Money Order } \\
\hline & & .05 & $* * *$ & -.02 & $*$ & .05 & $*$ & .08 & $* * *$ & -.01 & & .00 & & -.01 & & .00 & \\
\hline \multirow{9}{*}{ Characterisitcs } & Convenience & .08 & $* * *$ & .04 & $* * *$ & .04 & & .10 & $* * *$ & .02 & $* * *$ & -.01 & & .02 & $*$ & .06 & $* * *$ \\
\hline & Records & .03 & $* * *$ & .01 & & .03 & & .02 & & .01 & * & .03 & & .00 & & .01 & \\
\hline & Speed Time at Checkout & .02 & & .04 & $* * *$ & .06 & & .04 & & .02 & $*$ & .05 & $* * *$ & .02 & $* *$ & .00 & \\
\hline & Speed Deduct & .01 & & -.05 & $* * *$ & -.01 & & .02 & & .01 & & -.02 & & -.02 & & -.01 & \\
\hline & Speed Notify & -.01 & & .01 & & .03 & & .03 & & .02 & $*$ & -.02 & & .00 & & -.01 & \\
\hline & Speed Receipt & .02 & & -.01 & & -.02 & & -.02 & & .00 & & .00 & & -.01 & & .00 & \\
\hline & Security Wealth & .00 & & .00 & & .05 & $* * *$ & .06 & $* * *$ & -.01 & $* *$ & .01 & & -.02 & $* * *$ & -.01 & \\
\hline & Security PII & .01 & & .02 & $* *$ & .01 & & -.01 & & -.01 & $*$ & .03 & $* *$ & .01 & $*$ & .02 & \\
\hline & Security Confidentiality & .01 & & .01 & & -.01 & & -.03 & $*$ & .01 & & -.01 & & .00 & & .02 & \\
\hline \multirow{5}{*}{ Age } & Under 25 & -.09 & $* * *$ & .03 & & .01 & & .06 & & .02 & & -.01 & & .00 & & -.07 & $*$ \\
\hline & $25-34$ & -.03 & & .00 & & -.02 & & .10 & $* * *$ & .01 & & -.03 & $* *$ & -.02 & & -.05 & $* * *$ \\
\hline & $45-54$ & .01 & & .01 & & -.05 & $* *$ & .02 & & .01 & & .01 & & .00 & & .00 & \\
\hline & $55-64$ & .00 & & .02 & & -.02 & & .01 & & .00 & & .03 & $* *$ & .00 & & .01 & \\
\hline & 65 or Over & -.02 & & .03 & $* *$ & -.05 & & .05 & & .00 & & .00 & & .00 & & .06 & $*$ \\
\hline & Less than High School & .11 & $* * *$ & .02 & & .03 & & .00 & & .04 & $* *$ & -.03 & & .01 & & -.08 & $* *$ \\
\hline & High School & .02 & & .03 & $* * *$ & .04 & & -.04 & $*$ & .00 & & -.01 & & .02 & & -.03 & \\
\hline Education & Some College & .02 & & .01 & & .04 & $* *$ & -.02 & & -.01 & & -.01 & & .02 & $* *$ & -.01 & \\
\hline & Post Graduate & .01 & & .01 & & .00 & & .00 & & .00 & & -.01 & & .01 & & -.02 & \\
\hline & Never Married & .05 & $* * *$ & -.01 & & .02 & & .00 & & -.01 & & -.01 & & .01 & & .03 & \\
\hline Marital Status & Separated or Divorced & .01 & & .00 & & .02 & & -.01 & & -.02 & $*$ & .03 & $* *$ & .01 & & -.01 & \\
\hline & Widowed & -.02 & & .00 & & .09 & $* *$ & -.04 & & -.01 & & -.01 & & -.01 & & -.03 & \\
\hline & Household Size & .00 & & .00 & & .01 & $*$ & .00 & & .00 & & .00 & & .00 & & .00 & \\
\hline Ethnicity & Latino & .02 & & .01 & & .03 & & -.04 & $* *$ & .02 & & -.01 & & .01 & & -.01 & \\
\hline & Black & .02 & & .01 & & .07 & $* * *$ & -.05 & $*$ & .04 & $* * *$ & .01 & & .02 & & .03 & \\
\hline Race & Asian & -.02 & & .01 & & -.11 & $* *$ & .12 & $* * *$ & .04 & $*$ & -.03 & & .01 & & .00 & \\
\hline & Other & .03 & & -.02 & & .03 & & .03 & & -.02 & $*$ & -.03 & * & -.03 & $* *$ & -.01 & \\
\hline Gender & Male & .04 & $* * *$ & -.02 & $* * *$ & -.01 & & -.01 & & -.01 & & -.01 & & .00 & & -.03 & $*$ \\
\hline & $<\$ 25,000$ & .08 & $* * *$ & .01 & & .06 & $* *$ & -.04 & $*$ & .03 & $* * *$ & .02 & & -.01 & & .00 & \\
\hline Income & $\$ 25,000-\$ 49,000$ & .01 & & .02 & & .02 & & -.02 & & .00 & & -.01 & & .01 & & .03 & $*$ \\
\hline Income & $\$ 75,000-\$ 99,999$ & -.04 & $* *$ & .00 & & .02 & & .01 & & .01 & & .01 & & .01 & & -.01 & \\
\hline & $>=\$ 100,000$ & -.02 & & .01 & & -.04 & & .02 & & .01 & & .00 & & .01 & & .03 & \\
\hline & Not Highest Income In Household & .03 & $* * *$ & -.01 & $*$ & .00 & & -.02 & & -.01 & & .00 & & -.01 & & -.02 & \\
\hline & $<\$ 50,000$ & -.02 & & .00 & & .01 & & -.01 & & .00 & & .00 & & .01 & & .04 & \\
\hline & $\$ 50,000-\$ 100,000$ & -.01 & & .01 & & .02 & & .00 & & .01 & & .02 & & -.01 & & .02 & \\
\hline Net Worth & $\$ 250,000-\$ 399,999$ & -.03 & & .00 & & -.01 & & .07 & $* * *$ & .01 & & -.01 & & -.01 & & .03 & \\
\hline & $>=\$ 500,000$ & -.01 & & .01 & & -.05 & $*$ & .06 & $* * *$ & .01 & & -.01 & & .00 & & .00 & \\
\hline & Missing Net Worth & .04 & & -.01 & & .03 & & .00 & & .01 & & -.02 & & .00 & & .01 & \\
\hline & Retired & .00 & & .00 & & -.05 & $*$ & .03 & & -.01 & & .02 & & .00 & & -.04 & \\
\hline & Disabled & .00 & & .03 & & -.02 & & .11 & $* * *$ & .02 & & -.05 & $* *$ & -.01 & & .02 & \\
\hline Employment Status & Unemployed & .00 & & .00 & & .03 & & .07 & $* *$ & -.01 & & -.02 & & .01 & & .02 & \\
\hline & Homemaker & .02 & & .00 & & .01 & & .00 & & -.03 & $* *$ & .01 & & -.01 & & .15 & $* * *$ \\
\hline & Other & .01 & & .01 & & -.09 & & .17 & $* * *$ & -.01 & & -.05 & $*$ & .00 & & -.01 & \\
\hline Financial & Pay Bills & .00 & & .00 & & -.01 & & .00 & & .00 & & .00 & & .00 & & .02 & $* * *$ \\
\hline Responsibility & Shops & .00 & & .00 & & .00 & & .00 & & .00 & & .00 & & .00 & & -.01 & $* *$ \\
\hline & Born Abroad & -.01 & & -.02 & & -.04 & & .03 & & -.02 & & .02 & & .00 & & -.01 & \\
\hline & Fewer than Three & .23 & $* * *$ & .08 & $* * *$ & .03 & & .01 & & .09 & $* * *$ & -.04 & & .06 & & .08 & $* * *$ \\
\hline Number of Uther & Four & .00 & & -.07 & $* * *$ & -.03 & & -.07 & $* * *$ & -.03 & $* *$ & -.02 & & .02 & $*$ & .00 & \\
\hline $\begin{array}{l}\text { Payment } \\
\text { Instruments }\end{array}$ & Five & -.04 & $* *$ & -.10 & $* * *$ & -.05 & $* *$ & -.05 & $* *$ & -.02 & $* *$ & -.04 & $* *$ & .00 & & -.04 & \\
\hline Instruments & $\operatorname{Six}$ & -.04 & $*$ & -.11 & $* * *$ & -.09 & $* * *$ & -.06 & $* * *$ & -.02 & & -.06 & $* * *$ & .00 & & -.03 & \\
\hline & Seven & .00 & & -.14 & $* * *$ & -.09 & $* *$ & -.07 & $*$ & -.02 & & -.05 & $* *$ & -.03 & $*$ & -.04 & \\
\hline & Revolved on Credit & -.02 & $*$ & .03 & $* * *$ & .05 & $* * *$ & -.11 & $* * *$ & -.01 & & .01 & & .02 & $* * *$ & -.03 & $*$ \\
\hline & Inverse Mills Ratio & & & -.07 & **** & -.22 & *** & -.03 & & .05 & & -.04 & & -.04 & & .01 & \\
\hline & Number of Observations & 1779 & & 1764 & & 1765 & & 1765 & & 1763 & & 1751 & & 1712 & & 1762 & \\
\hline & Adjusted R-Squared (CHAR) & .31 & & .27 & & .26 & & .36 & & .20 & & .12 & & .10 & & .14 & \\
\hline & Adjusted R-Squared (No CHAR) & .28 & & .23 & & .24 & & .30 & & .18 & & .10 & & .09 & & .13 & \\
\hline
\end{tabular}




\section{Appendix Table 4: Adoption, Following Kahn and Liñares-Zegarra Methodology}

\begin{tabular}{|c|c|c|c|c|c|c|c|c|c|c|c|c|c|c|c|}
\hline \multirow[t]{2}{*}{ Categories } & \multirow{2}{*}{$\begin{array}{l}\text { Variables } \\
\text { Acceptance }\end{array}$} & \multirow{2}{*}{$\begin{array}{r}\text { Check } \\
0.00\end{array}$} & \multicolumn{2}{|r|}{ Debit } & \multicolumn{2}{|r|}{ Credit } & \multicolumn{2}{|r|}{ Prepaid } & \multicolumn{2}{|c|}{ OBBP } & \multicolumn{2}{|c|}{ BANP } & \multicolumn{3}{|c|}{ Money Order } \\
\hline & & & & 0.05 & & -0.07 & $*$ & 0.11 & $* * *$ & 0.06 & & 0.00 & & 0.07 & $* * *$ \\
\hline \multirow{9}{*}{ Characterisitcs } & Cost & 0.03 & $*$ & 0.10 & $* * *$ & 0.06 & $* * *$ & -0.04 & & 0.20 & $* * *$ & 0.11 & $* *$ & 0.03 & \\
\hline & Convenience & 0.01 & & 0.12 & $* * *$ & 0.15 & $* * *$ & 0.00 & & 0.28 & $* * *$ & 0.08 & $* *$ & 0.06 & $* * *$ \\
\hline & Setup & 0.05 & $* * *$ & 0.12 & $* * *$ & 0.15 & $* * *$ & -0.01 & & 0.16 & $* * *$ & 0.07 & & 0.10 & $* * *$ \\
\hline & Records & 0.04 & $* * *$ & 0.09 & $* * *$ & 0.17 & $* * *$ & -0.02 & & 0.19 & $* * *$ & 0.06 & & 0.04 & $*$ \\
\hline & Speed Time at Checkout & 0.00 & & 0.19 & $* * *$ & 0.07 & & 0.07 & & 0.16 & $* * *$ & 0.06 & & 0.03 & \\
\hline & Speed Deduct & 0.02 & & 0.04 & & 0.01 & & 0.03 & & 0.22 & $* * *$ & 0.26 & $* * *$ & 0.05 & $* *$ \\
\hline & Speed Notify & 0.00 & & 0.05 & & -0.03 & & 0.09 & $*$ & 0.08 & & -0.01 & & 0.12 & $* * *$ \\
\hline & Speed Receipt & 0.01 & & 0.07 & & -0.04 & & 0.04 & & -0.21 & $* * *$ & 0.10 & $* *$ & -0.07 & $* *$ \\
\hline & Security & -0.01 & & 0.05 & $* *$ & -0.04 & & -0.01 & & 0.14 & $* * *$ & 0.08 & $* * *$ & 0.04 & $*$ \\
\hline \multirow{5}{*}{ Age } & Under 25 & -0.02 & & 0.06 & & -0.08 & & -0.09 & & 0.16 & $* *$ & -0.02 & & -0.05 & \\
\hline & $25-34$ & -0.02 & & 0.00 & & -0.08 & $* *$ & -0.03 & & 0.06 & & 0.05 & & -0.02 & \\
\hline & $45-54$ & 0.00 & & 0.02 & & -0.01 & & -0.09 & $* *$ & -0.03 & & -0.01 & & -0.06 & $* *$ \\
\hline & $55-64$ & 0.03 & $* * *$ & -0.01 & & -0.01 & & -0.08 & $*$ & -0.04 & & 0.01 & & -0.03 & \\
\hline & 65 or Over & 0.03 & $* * *$ & -0.03 & & 0.02 & & -0.17 & $* * *$ & -0.07 & & -0.07 & & -0.07 & $* *$ \\
\hline \multirow{4}{*}{ Education } & Less than High School & -0.08 & $*$ & -0.28 & $* * *$ & -0.20 & $* *$ & -0.04 & & -0.13 & & -0.26 & $* * *$ & -0.02 & \\
\hline & High School & -0.07 & $* * *$ & -0.07 & $* *$ & -0.13 & $* * *$ & -0.15 & $* * *$ & -0.05 & & -0.10 & $* *$ & -0.04 & \\
\hline & Some College & -0.05 & $* * *$ & -0.01 & & -0.09 & $* * *$ & -0.04 & & -0.03 & & -0.04 & & 0.03 & \\
\hline & Graduate Degree & 0.02 & $*$ & -0.04 & & 0.06 & $* *$ & 0.08 & $* *$ & -0.02 & & 0.06 & & 0.00 & \\
\hline \multirow{4}{*}{ Marital Status } & Never Married & -0.02 & $*$ & -0.08 & $* *$ & -0.07 & $* *$ & 0.02 & & 0.01 & & -0.11 & $* * *$ & 0.00 & \\
\hline & Separated Divorced & -0.04 & $* *$ & -0.03 & & -0.08 & $* *$ & 0.02 & & 0.03 & & -0.03 & & -0.02 & \\
\hline & Widowed & 0.01 & & -0.04 & & 0.01 & & -0.08 & & 0.08 & & 0.11 & $* *$ & -0.02 & \\
\hline & Household Size & 0.00 & & -0.01 & & -0.03 & $* * *$ & 0.01 & & 0.01 & & 0.00 & & 0.00 & \\
\hline Ethnicity & Latino & -0.03 & $* *$ & 0.02 & & -0.02 & & 0.14 & $* * *$ & 0.07 & & -0.02 & & 0.02 & \\
\hline & Black & -0.07 & $* * *$ & 0.00 & & -0.12 & $* * *$ & -0.04 & & 0.02 & & -0.05 & & 0.20 & $* * *$ \\
\hline Race & Asian & 0.03 & $* * *$ & 0.08 & $* *$ & 0.06 & & 0.12 & & -0.05 & & 0.08 & & 0.03 & \\
\hline & Other & -0.01 & & -0.05 & & -0.05 & & -0.10 & $*$ & 0.04 & & -0.01 & & 0.06 & \\
\hline Gender & Male & -0.02 & $* *$ & -0.02 & & -0.03 & & -0.08 & $* * *$ & 0.03 & & -0.05 & $* *$ & -0.04 & $* *$ \\
\hline & $<\$ 25,000$ & -0.17 & $* * *$ & -0.14 & $* * *$ & -0.19 & $* * *$ & 0.06 & & -0.19 & $* * *$ & -0.19 & $* * *$ & -0.02 & \\
\hline Income & $\$ 25,000-\$ 49,999$ & -0.07 & $* * *$ & -0.03 & & -0.04 & & 0.00 & & -0.02 & & -0.05 & & 0.02 & \\
\hline Income & $\$ 75,000-\$ 99,999$ & -0.07 & $*$ & -0.02 & & 0.07 & $* *$ & 0.09 & $*$ & 0.04 & & -0.02 & & -0.04 & \\
\hline & $>=\$ 100,000$ & -0.04 & & -0.02 & & 0.07 & $* *$ & 0.14 & $* * *$ & 0.07 & & 0.00 & & 0.06 & $*$ \\
\hline & Not Highest Income In Household & 0.00 & & 0.03 & & -0.03 & & -0.01 & & 0.00 & & 0.01 & & -0.02 & \\
\hline & $<\$ 50,000$ & -0.02 & & 0.03 & & 0.04 & & 0.00 & & -0.02 & & 0.01 & & 0.08 & $* * *$ \\
\hline & $\$ 50,000-\$ 100,000$ & -0.03 & & -0.03 & & 0.03 & & -0.04 & & -0.01 & & 0.02 & & 0.06 & \\
\hline Net Worth & $\$ 250,000-\$ 399,999$ & 0.01 & & -0.08 & $*$ & 0.08 & $* * *$ & 0.10 & $* *$ & 0.04 & & -0.05 & & 0.04 & \\
\hline & $>=\$ 500,000$ & 0.02 & & -0.12 & $* * *$ & 0.04 & & 0.11 & $* * *$ & 0.02 & & -0.01 & & -0.03 & \\
\hline & Missing Net Worth & -0.03 & & -0.11 & & 0.01 & & 0.04 & & 0.04 & & 0.03 & & 0.11 & \\
\hline & Retired & 0.01 & & -0.01 & & 0.06 & $*$ & 0.01 & & 0.04 & & -0.03 & & -0.02 & \\
\hline & Disabled & -0.03 & & -0.02 & & -0.05 & & 0.29 & $* * *$ & -0.03 & & -0.09 & & 0.11 & $* *$ \\
\hline Employmemi & Unemployed & -0.05 & $* *$ & -0.12 & $* * *$ & -0.09 & $* *$ & 0.07 & & -0.07 & & -0.08 & $*$ & 0.01 & \\
\hline & Homemaker & -0.04 & & -0.11 & $*$ & -0.07 & & -0.03 & & -0.07 & & -0.12 & $*$ & -0.02 & \\
\hline & Other & -0.07 & & -0.06 & & -0.10 & & 0.04 & & 0.02 & & 0.10 & & 0.12 & \\
\hline & Pay Bills & 0.01 & & 0.01 & & 0.02 & $*$ & 0.01 & & 0.02 & $* *$ & 0.04 & $* * *$ & 0.01 & \\
\hline & Shops & 0.00 & & 0.01 & & 0.01 & & 0.02 & $*$ & 0.00 & & -0.01 & & -0.01 & \\
\hline & Born Abroad & 0.01 & & 0.03 & & 0.00 & & -0.10 & $* *$ & 0.03 & & -0.04 & & 0.03 & \\
\hline & Homeowner & 0.03 & $* *$ & 0.03 & & 0.10 & $* * *$ & -0.05 & & 0.07 & $*$ & 0.10 & $* * *$ & -0.05 & $* *$ \\
\hline & Ever Bankrupt (last 12 months) & -0.01 & & -0.07 & & 0.07 & & 0.01 & & 0.00 & & -0.14 & & 0.03 & \\
\hline & Ever Bankrupt (last 7 years) & 0.00 & & 0.06 & & -0.29 & $* * *$ & 0.02 & & 0.04 & & 0.14 & $* * *$ & 0.05 & \\
\hline & $\begin{array}{l}\text { Yes, myself and } \\
\text { someone I know well }\end{array}$ & -0.02 & & 0.03 & & -0.02 & & 0.02 & & 0.08 & & -0.06 & & 0.09 & * \\
\hline ID Theft & Yes, someone I know well & -0.03 & $*$ & 0.01 & & 0.00 & & 0.03 & & 0.02 & & 0.02 & & 0.06 & * \\
\hline & Yes, myself only & -0.01 & & -0.04 & & -0.02 & & -0.03 & & -0.07 & & 0.03 & & -0.01 & \\
\hline & Number of Observations & 1838 & & 1838 & & 1835 & & 1837 & & 1823 & & 1779 & & 1832 & \\
\hline & R-Squared (CHAR) & 0.45 & & 0.28 & & 0.43 & & 0.09 & & 0.24 & & 0.16 & & 0.21 & \\
\hline & R-Squared (No CHAR) & 0.42 & & 0.14 & & 0.36 & & 0.08 & & 0.10 & & 0.12 & & 0.15 & \\
\hline
\end{tabular}




\section{Appendix Table 5: Use, Following Kahn and Liñares-Zegarra Methodology}

\begin{tabular}{|c|c|c|c|c|c|c|c|c|c|c|c|c|c|c|c|c|c|}
\hline \multirow{2}{*}{ Categories } & \multirow{2}{*}{$\begin{array}{l}\text { Variables } \\
\text { Cost }\end{array}$} & \multicolumn{2}{|c|}{ Cash } & \multicolumn{2}{|c|}{ Check } & \multicolumn{2}{|c|}{ Debit } & \multicolumn{2}{|c|}{ Credit } & \multicolumn{2}{|c|}{ Prepaid } & \multicolumn{2}{|c|}{ OBBP } & \multicolumn{2}{|c|}{ BANP } & \multicolumn{2}{|c|}{ Money Order } \\
\hline & & 0.05 & $* * *$ & -0.02 & & 0.04 & & 0.08 & $* * *$ & -0.01 & & -0.02 & & -0.02 & & 0.00 & \\
\hline \multirow{7}{*}{ Characterisitcs } & Convenience & 0.08 & $* * *$ & 0.04 & $* * *$ & 0.03 & & 0.10 & $* * *$ & 0.02 & $* * *$ & -0.03 & & 0.02 & $* *$ & 0.06 & $* * *$ \\
\hline & Records & 0.03 & $* * *$ & 0.01 & & 0.02 & & 0.04 & & 0.01 & * & 0.02 & & 0.00 & & 0.00 & \\
\hline & Speed at Time of Pay & 0.02 & & 0.04 & $* * *$ & 0.07 & * & 0.04 & & 0.02 & & 0.05 & $* * *$ & 0.02 & $* *$ & 0.00 & \\
\hline & Speed Deduct & 0.01 & & -0.05 & $* * *$ & 0.01 & & 0.03 & & 0.01 & & -0.02 & & -0.03 & & -0.01 & \\
\hline & Speed Notify & -0.01 & & 0.02 & & 0.03 & & 0.03 & * & 0.02 & * & -0.02 & & 0.00 & & 0.00 & \\
\hline & Speed Receipt & 0.02 & & -0.01 & & -0.02 & & -0.03 & & 0.00 & & 0.00 & & -0.01 & & 0.00 & \\
\hline & Security & 0.01 & & 0.03 & $* * *$ & 0.07 & $* * *$ & 0.00 & & -0.01 & $*$ & 0.02 & $*$ & 0.00 & & 0.02 & \\
\hline & Under 25 & -0.09 & $* * *$ & 0.03 & & 0.01 & & 0.06 & & 0.02 & & -0.02 & & 0.00 & & -0.07 & $*$ \\
\hline & $25-34$ & -0.03 & & -0.01 & & -0.02 & & 0.10 & $* * *$ & 0.01 & & -0.02 & $* *$ & -0.01 & & -0.05 & $* *$ \\
\hline Age & $45-54$ & 0.01 & & 0.01 & & -0.05 & $* *$ & 0.02 & & 0.01 & & 0.02 & & 0.00 & & 0.00 & \\
\hline & $55-64$ & 0.00 & & 0.02 & & -0.02 & & 0.01 & & 0.00 & & 0.03 & $* * *$ & 0.01 & & 0.01 & \\
\hline & 65 or Over & -0.02 & & 0.04 & $* *$ & -0.05 & & 0.04 & & 0.01 & & 0.01 & & 0.00 & & 0.06 & $*$ \\
\hline & Less than High School & 0.11 & $* * *$ & 0.02 & & 0.03 & & 0.00 & & 0.04 & ** & -0.02 & & 0.02 & & -0.07 & $* *$ \\
\hline & High School & 0.02 & & 0.03 & $* * *$ & 0.03 & & -0.04 & $* *$ & 0.00 & & 0.00 & & 0.02 & $*$ & -0.02 & \\
\hline Education & Some College & 0.02 & & 0.01 & & 0.03 & $*$ & -0.03 & & 0.00 & & -0.01 & & 0.02 & $* * *$ & 0.00 & \\
\hline & Post Graduate & 0.01 & & 0.01 & & 0.00 & & 0.00 & & 0.00 & & -0.01 & & 0.01 & & -0.02 & \\
\hline & Never Married & 0.05 & $* * *$ & -0.02 & $*$ & 0.02 & & 0.01 & & -0.01 & & 0.00 & & 0.01 & & 0.03 & \\
\hline Marital Status & Separated or Divorced & 0.01 & & 0.00 & & 0.02 & & 0.00 & & -0.02 & $*$ & 0.03 & $* *$ & 0.01 & & -0.01 & \\
\hline & Widowed & -0.02 & & 0.00 & & 0.09 & $* *$ & -0.04 & & -0.01 & & -0.01 & & -0.01 & & -0.03 & \\
\hline & Household Size & 0.00 & & 0.00 & & 0.01 & $*$ & 0.00 & & 0.00 & & 0.00 & & 0.00 & & 0.00 & \\
\hline Ethnicity & Latino & 0.02 & & 0.01 & & 0.03 & & -0.05 & ** & 0.02 & & -0.01 & & 0.01 & & -0.02 & \\
\hline & Black & 0.02 & & 0.01 & & 0.07 & $* * *$ & -0.05 & ** & 0.04 & $* * *$ & 0.01 & & 0.02 & & 0.04 & \\
\hline Race & Asian & -0.02 & & 0.01 & & -0.12 & $* * *$ & 0.12 & $* * *$ & 0.03 & $*$ & -0.03 & & 0.01 & & 0.01 & \\
\hline & Other & 0.04 & $*$ & -0.02 & & 0.02 & & 0.03 & & -0.02 & * & -0.03 & $* *$ & -0.02 & * & 0.00 & \\
\hline Gender & Male & 0.04 & $* * *$ & -0.02 & $* * *$ & -0.02 & & -0.01 & & -0.01 & & -0.01 & & 0.00 & & -0.03 & $*$ \\
\hline & $<\$ 25,000$ & 0.08 & $* * *$ & 0.01 & & 0.05 & $* *$ & -0.04 & & 0.03 & $* * *$ & 0.03 & & -0.01 & & 0.00 & \\
\hline Income & $\$ 25,000-\$ 49,000$ & 0.01 & & 0.02 & & 0.03 & & -0.02 & & 0.00 & & -0.01 & & 0.01 & & 0.03 & \\
\hline Income & $\$ 75,000-\$ 99,999$ & -0.04 & $* *$ & 0.00 & & 0.02 & & 0.01 & & 0.01 & & 0.00 & & 0.01 & & -0.01 & \\
\hline & $>=\$ 100,000$ & -0.02 & & 0.01 & & -0.04 & $*$ & 0.03 & & 0.01 & & 0.00 & & 0.00 & & 0.03 & \\
\hline & Not Highest Income In Household & 0.03 & $* * *$ & -0.01 & * & 0.00 & & -0.02 & & -0.01 & & 0.00 & & -0.01 & & -0.02 & \\
\hline & $<\$ 50,000$ & -0.02 & & 0.00 & & 0.01 & & 0.00 & & 0.00 & & 0.01 & & 0.01 & & 0.03 & \\
\hline & $\$ 50,000-\$ 100,000$ & -0.01 & & 0.00 & & 0.02 & & -0.01 & & 0.01 & & 0.02 & & -0.01 & & 0.03 & \\
\hline Net Worth & $\$ 250,000-\$ 399,999$ & -0.03 & & 0.00 & & -0.01 & & 0.07 & $* * *$ & 0.01 & & -0.01 & & -0.01 & & 0.02 & \\
\hline & $>=\$ 500,000$ & -0.01 & & 0.01 & & -0.05 & $*$ & 0.07 & $* * *$ & 0.01 & & 0.00 & & 0.00 & & -0.01 & \\
\hline & Missing Net Worth & 0.04 & & -0.01 & & 0.04 & & 0.00 & & 0.01 & & -0.03 & & -0.01 & & 0.01 & \\
\hline & Retired & 0.00 & & 0.00 & & -0.05 & $*$ & 0.03 & & -0.01 & & 0.02 & & 0.00 & & -0.03 & \\
\hline & Disabled & 0.00 & & 0.03 & & -0.02 & & 0.11 & $* * *$ & 0.02 & & -0.04 & $*$ & -0.01 & & 0.02 & \\
\hline Employment Status & Unemployed & 0.01 & & 0.00 & & 0.02 & & 0.06 & $* *$ & -0.01 & & -0.02 & & 0.00 & & 0.02 & \\
\hline & Homemaker & 0.02 & & 0.00 & & 0.00 & & 0.00 & & -0.03 & $* *$ & 0.02 & & -0.01 & & 0.15 & $* * *$ \\
\hline & Other & 0.01 & & 0.01 & & -0.08 & & 0.16 & $* * *$ & -0.01 & & -0.05 & * & 0.00 & & 0.00 & \\
\hline Financial & Pay Bills & 0.00 & & 0.00 & & -0.01 & & 0.00 & & 0.00 & & 0.00 & & 0.00 & & 0.01 & $* *$ \\
\hline Responsibility & Shops & 0.00 & & 0.00 & & 0.00 & & 0.00 & & 0.00 & & 0.00 & & 0.00 & & -0.01 & $*$ \\
\hline & $\begin{array}{l}\text { Yes, myself and } \\
\text { someone I know well }\end{array}$ & -0.03 & & 0.00 & & -0.03 & & 0.03 & & 0.00 & & -0.02 & & 0.00 & & 0.04 & $*$ \\
\hline ID Theft & Yes, someone I know well & 0.00 & & 0.02 & & 0.00 & & -0.03 & $*$ & 0.00 & & 0.01 & & 0.00 & & 0.02 & \\
\hline & Yes, myself only & 0.03 & & -0.02 & & 0.06 & $*$ & 0.00 & & 0.01 & & -0.02 & & -0.05 & $* * *$ & -0.02 & \\
\hline & Born Abroad & -0.01 & & -0.02 & & -0.03 & & 0.03 & & -0.02 & & 0.02 & & 0.00 & & 0.00 & \\
\hline & Fewer than Three & 0.24 & $* * *$ & 0.08 & $* * *$ & 0.03 & & 0.00 & & 0.09 & $* * *$ & -0.03 & & 0.05 & & 0.08 & $* * *$ \\
\hline Number of Uther & Four & 0.00 & & -0.07 & $* * *$ & -0.03 & & -0.07 & $* * *$ & -0.02 & $*$ & -0.02 & & 0.02 & & 0.00 & \\
\hline Instruments & Five & -0.04 & $* *$ & -0.10 & $* * *$ & -0.05 & $*$ & -0.05 & $* *$ & -0.02 & * & -0.04 & $* *$ & 0.00 & & -0.04 & \\
\hline Instruments & Six & -0.04 & $*$ & -0.11 & $* * *$ & -0.09 & $* * *$ & -0.06 & $* *$ & -0.01 & & -0.05 & $* * *$ & 0.00 & & -0.03 & \\
\hline & Seven & 0.00 & & -0.13 & $* * *$ & -0.09 & $* *$ & -0.06 & * & -0.02 & & -0.05 & $* *$ & -0.03 & $*$ & -0.04 & \\
\hline & Revolved on Credit & -0.02 & $*$ & 0.03 & $* * *$ & 0.06 & $* * *$ & -0.11 & $* * *$ & -0.01 & & 0.01 & & 0.02 & $* * *$ & -0.03 & $* *$ \\
\hline & Inverse Mills Ratio & & & -0.06 & *** & -0.20 & *** & -0.05 & & 0.04 & & -0.07 & *** & -0.05 & & 0.01 & \\
\hline & Number of Observations & 1779 & & 1769 & & 1770 & & 1766 & & 1768 & & 1755 & & 1714 & & 1764 & \\
\hline & Adjusted R-Squared (CHAR) & 0.32 & & 0.27 & & 0.25 & & 0.35 & & 0.20 & & 0.11 & & 0.10 & & 0.14 & \\
\hline & Adjusted R-Squared (No CHAR) & 0.28 & & 0.23 & & 0.23 & & 0.30 & & 0.18 & & 0.10 & & 0.09 & & 0.14 & \\
\hline
\end{tabular}

